\title{
Column
}

\section{Taking the 'hard' out of hearing on the job: Working with hearing loss}

\author{
Gael Hannan \\ Hannan Consulting, 24 Donalbert Road, Etobicoke, Ontario, M9B 2E8, Canada \\ E-mail: gaelh@rogers.com
}

Received 15 March 2012

Accepted 7 November 2012

\section{Author information}

Gael Hannan is a renowned Canadian hearing health advocate. She is the Consumer Editor (The Happy Hoh) for the Canadian Hearing Report, and writes a weekly blog for the esteemed hearinghealthmatters.org. Gael uses drama and humour to illustrate the impact of hearing loss, in keynote workshops and performances that are delivered worldwide.

\section{Contact Information: gaelh@rogers.com}

Living with a severe and permanent hearing loss has affected every corner of my life, including my working life. You can't make out the name of the client on the phone. The boss yells out instructions as he's walking away. There are 15 people sitting around the boardroom table and you can't follow the conversation. PA announcements are unintelligible. The office is a mass of cubicles, poor sightlines and constant noise, creating a roar in your hearing aids.

This is the often-nightmare world of working with a sensory disability. Yet, this scenario is easily transformed from nightmare to dream world thanks to the explosion in communication technology and new accessibility laws that have improved workplace access and eliminated barriers for hard of hearing people.

Diagnosed at age two, my congenital hearing loss is now severe-to-profound which means that without my hearing aids I hear only slamming doors and explosions - if they're close enough. I didn't have a hearing aid until I was 20, courtesy of the prevailing hearing health wisdom of the time, but as my hearing loss was relatively mild as a child, my speech developed well, assisted by drama lessons in my early teens. My parents taught me to let people know that I needed them to speak up or face me. If I didn't self-identify, my mother would do it for me, "You need to face Gael when you speak to her." I hated that, and to this day I prefer to disclose my own needs. My family had a collective sense of humour about my hearing loss, although they found my "mis-hears" much funnier than I did. But this positive family attitude instilled the knowledge that my hearing loss was simply a part of me, not the sum total.

Apart from my family's support, I grew up without the resources considered mandatory for hard of hearing children today. There was no aural rehabilitation, hearing resource teachers, or role models. Accommodation meant sitting at the front of the class (the very front - for over 10 years I looked up the noses of every elementary and high school teacher). Without professional guidance, I developed my own communication strategies, often without realizing it. I became an expert speechreader, although this is an imperfect tool because less than $50 \%$ of speech movements are visible on the lips. Because I depended so much on visual cues, I'm sure that my speechreading improved immensely when I got glasses in Grade 6. 
I was adept at creating support systems, and I still use other people to do my hearing for me in difficult listening situations, by having them translate or relay the information that I am missing. I prefer to get my information first-hand, but if I need help, I don't hesitate to call in the troops and use any available means to connect.

\section{Workplace challenges}

In my first high-school job in a dry cleaning store, I experienced my first work-related communication barriers. As I took down the customer names and phone numbers on the ticket, I couldn't read their lips, so I learned to write, albeit badly, without looking at the paper. Most people look down as you write to make sure you're spelling their name correctly, and customers usually did not notice my innovative strategy. But if someone looked up during the process, they were shocked to find me staring intently at their face.

Changing doctors at age 20, I had a hearing aid within a month and life suddenly became much louder. Increased volume doesn't necessarily translate to better speech comprehension but it was a major improvement for my by now moderate hearing loss.

After high school, I worked in a busy hospital clinic and effective communication was challenging; on the phone I would often get numbers and names wrong, because after saying 'pardon?' a couple of times, I would just give it my best guess. (Bluffing is a hallmark of hearing loss, often landing us in hot water. I wasn't even certain that my husband was proposing to me, but I made a lucky guess.) But as my hearing loss worsened, the quality of my hearing aids improved and so did my marketing career. Applying for my dream job with the Australian Tourism Commission, my resumé did not mention my hearing loss, but focused on how my skills met the job requirements. This job interview was the first in which I was open and matter-offact about my hearing loss. I asked the three interviewers (another hearing loss nightmare) to shift the seating arrangements to give me better sightlines and conversation flow. By taking control of the communication situation, they understood that I was comfortable with my hearing loss and knew how to have my needs met, a good sign to an employer. I got the job.

\section{Reaching out for support}

Some of life's events only gain significance with hindsight, "Wow THAT sure changed my life!" One of those invisible forks in the road occurred when I attended my first gathering of hard of hearing people. I was pregnant and worried about how I was going to cope as a hard of hearing mom. How would I hear my baby crying in the night? If I didn't hear him burp, would he blow up? I needed answers.

The three-day conference gave me answers, new friends, and a revelation. In spite of my affirmative upbringing, I had always felt an inner shame about my hearing loss that affected both my personal and working lives. I had moved through my adult life ignorant of both the emerging assistive technology, as well as the fact that it was ok to ask for access. And now, by connecting with other hard of hearing people, that shame was permanently replaced with a new perspective and a healthier respect for technology which I embraced with the fervour of the newly-converted.

I moved from one hearing aid to two, which gave me more volume and clarity. Captioning and print interpretation of all types became a must-have for television, movies, at meetings, and when giving workshops. My newest hearing aids have a telecoil, which connects to phones of all types, personal listening devices, and FM and loop systems. Computer communication such as email and Skype have mobilized and connected workers with hearing loss at a level undreamed of just a few short years ago.

\section{Today...}

I live and breathe hearing loss. It has become not only my issue, but my career. I am a writer, consultant and project manager on hearing loss-related projects for organizations such as the Canadian Hearing Society, the Canadian Hard of Hearing Association, and the Hearing Foundation of Canada, and have written two manuals on working with hearing loss. I write a weekly consumer blog on hearinghealthmatters.org, and present communication workshops and my solo show Unheard Voices to audiences around North America.

While my science-challenged brain can't explain how hearing aids or FM technology work (I like to think of it as magic), I understand communication barriers and how to break them down. My work allows me to share positive strategies with other people with hearing loss, including those who struggle with communication challenges at work. When adult workers acquire hearing loss, they are often reluctant to disclose their difficulties for fear of backlash that could threaten 
their job or limit their chances of promotion. Employers worry about their employee's ability to cope in the workplace, or about the perceived high cost of accommodation.

I've learned that barriers are eliminated when the worker with hearing loss can say: I have hearing loss, and this is what I need to communicate well on the job, and the employer responds with, Let's do it!

It worked for me. 